\title{
ИЗМЕНЕНИЕ МИГРАЦИИ ХИМИЧЕСКИХ ЭЛЕМЕНТОВ В РАЙОНЕ РАЗМЕЩЕНИЯ ПРЕДПРИЯТИЯ НЕФТЕПЕРЕРАБОТКИ
}

\author{
Боев Владислав Викторович1, \\ v.-3@mail.ru
}

\section{Барановская Наталья Владимировна²,} natalya.baranovs@mail.ru

Боев Виктор Александрович1,
vikboev2009@mail.ru

1 Тюменский государственный университет,

Россия, 625003, г. Тюмень, ул. Володарского, 6.

2 Национальный исследовательский Томский политехнический университет, Россия, 634050, г. Томск, пр. Ленина, 30.

\begin{abstract}
Актуальность исследования обусловлена отсутствием данных по воздействию многих нефтеперерабатывающих заводов на прилегающие почвы для конкретных регионов, определяемому конструктивными и технологическими особенностями, при изученности общей геохимической специфики нефртеперерабатывающей отрасли.

Цель исследования состоит в выявлении особенностей накопления в почвах и распределения по профилю некоторых специфических для нефтеперерабатывающей промышленности химических элементов на территории деятельности относительно нового нефтеперерабатывающего завода путем сопоставления с данными для фоновой территории с аналогичными природными условиями и кларком.

объекты: почвы Тюменского федерального заказника и территории расположения Антипинского нефртеперерабатьвающего завода.

Методы: выбор и подготовка пробных площадок, отбор и подготовка почв, определение элементного состава инструментальным нейтронно-активационным методом, интерпретация результатов.

Результаты. Изучено содержание $\mathrm{Br}, \mathrm{Sb}, \mathrm{Zn}, \mathrm{As}$, Со в почвах восточной части Тюменского федерального заказника и района размещения Антипинского нефтеперерабатывающего завода, их распределение по профилю. Путем сравнения полученных результатов выявлено повышенное содержание данных химических элементов в горизонте А1 почв территории расположения Антипинского нефтеперерабатывающего завода относительно Тюменского федерального заказника и изменение закономерностей их распределения по профилю. В почве района вблизи техногенного объекта книзу сокращается повышенное содержание рассмотренных химических элементов, что наблюдается и по абсолютным значениям, и по коэфффициентам концентрации относительно условно-фоновых данных для почв Тюменского федерального заказника. Это свидетельствует о поступлении их с поверхности. При этом на обеих территориях содержание химических элементов ниже кларка, что отражает относительно невысокую техногенную нагрузку в данных районах.
\end{abstract}

\section{Ключевые слова:}

Элементный состав почв, Тюменский фредеральньй заказник, Антипинский нефтеперерабатьвающий завод, техногенное воздействие нефтепереработки на почвы, техногенная трансформация почв.

\section{Введение}

За время изучения изменения накопления и миграции химических элементов в природных средах под воздействием техногенеза установлена геохимическая специфика различных отраслей промышленности, включая нефтеперерабатывающую. Геоэкологическое значение последней определяется масштабами использования углеводородного сырья. Так, в мире функционирует более 800 нефтеперерабатывающих заводов [1] общей мощностью более 4 трлн т в год. Россия находится на 3 месте по первичной переработке нефти [2]. Здесь функционирует около 40 крупных нефтеперерабатывающих заводов общей мощность более 280 млн т в год [3].

Установлены различные механизмы поступления загрязняющих веществ от объектов нефтеперерабатывающей промышленности [4-9] и их воздействия на компоненты природной среды [10-20]. Выявлен ряд специфических химических элементов для нефтеперерабатывающей промышленности: $\mathrm{Br}, \mathrm{Sb}$, $\mathrm{La}, \mathrm{Tb}, \mathrm{Yb}, \mathrm{Ce}, \mathrm{As}, \mathrm{Hg}, \mathrm{Zn}, \mathrm{Co}$. Однако состав выбросов особенный для каждого нефтеперерабатывающего завода [21]. Это определяется рядом факторов, индивидуальных для каждого объекта, к которым относят технические и технологические характеристики [22]. На НПЗ выбросы разного состава исходят из множества источников с различными параметрами [23]. К тому же большинство исследований влияния нефтеперерабатывающей промышленности на природную среду сосредоточено на специфических для данной отрасли химических веществах вроде углеводородов и некоторых прочих химических соединениях [24].

Поэтому актуально детальное поэлементное изучение выбросов конкретных НПЗ и их распределения в определенных средах.

Загрязняющие вещества распространяются с выбросами от техногенных объектов в природных сре- 
дах. Для нефтеперерабатывающей промышленности преобладают атмосферные выбросы. Данная отрасль занимает 4 место по загрязнению атмосферы среди прочих [23]. Причем атмосферные выбросы местных НПЗ составляют 0,45 \% перерабатываемого сырья в сравнении с $0,1 \%$ западных предприятий. Поступление загрязняющих веществ в почву из атмосферы происходит путем их осаждения.

Компоненты природных сред обладают различными индикаторными свойствами, под которыми в эколого-геохимическом смысле понимают способность к отражению техногенной нагруженности территории путем накопления специфических химических элементов [25]. Так, почва отражает длительные тенденции техногенного воздействия. Важность изучения техногенного изменения данного компонента природной среды определяется несколькими факторами. Во-первых, сюда поступает значительная часть атмосферных выбросов, а также твердых и жидких компонентов с территорий техногенных объектов. Во-вторых, отсюда загрязняющие вещества усваиваются организмами и разносятся грунтовыми водами, поступая в литосферу и гидросферу. К тому же параметры почв, такие как строение профиля, гранулометрический состав и химические свойства, определяемые их типом, влияют на распространение техногенно поступающих химических элементов по разрезу.

Техногенное воздействие выявляют путем сравнения показателей содержания химических элементов в компонентах природной среды изучаемых территорий со значениями, принятыми за естественные. Последние могут быть представлены нормативными показателями (ПДК, ОДК), кларками, (средними значениями содержания химических элементов в определенном компоненте природной среды) или опытными значениями для фоновых территорий конкретных регионов. Ввиду региональной геохимической специфики наиболее корректной считают оценку техногенного воздействия на основе региональных фоновых данных. Однако в современных масштабах урбанизации и техногенеза затруднителен поиск фоновых территорий. Наиболее соответствующими фоновому статусу объектами считают особо охраняемые территории вроде заповедников и заказников.

\section{Материалы и методы}

Данная работа основана на сравнении элементного состава разрезов почв техногенной территории с фоновой для выявления изменения содержания и закономерностей распределения химических элементов. Использована территория размещения Антипинского нефтеперерабатывающего завода и участок Тюменского федерального заказника. Возможность применения последнего в качестве фоновой территории была подтверждена ранее [26].

Тюмень находится в зоне умеренно-континентального климата. На исследованных территориях преобладают смешанные, хвойные и лиственные леса с дерново-подзолистыми почвами и урбаноземами.

Антипинский НПЗ расположен на юго-восточной окраине г. Тюмени, где занимает территорию в 200 га.
Предприятие функционирует с 2006 г. Текущая производительность составляет 7,5 млн т в год. Для данного исследования была взята окружающая НПЗ территория радиусом чуть более 2 км. Ее произвольно подразделили по удаленности от объекта на 3 зоны (420-490, 700-1130, 1300-2170 м). Для отбора проб использовалась система концентрических окружностей [27]. С целью изучения специфики верхнего горизонта почвы ее отбирали из прикопок. Помимо этого, для отражения особенностей почвенной толщи, к югу от НПЗ, на наименее затронутой урбанизацией территории, во многом сохранившей естественный ландшафт, было создано три разреза. В Тюменском федеральном заказнике, принятом в данной работе за условно фоновую территорию, почвы отбирали на предварительно размеченной площадке в 0,25 га на основе методических рекомендаций [28]. Для исследования был выбран участок у восточной границы заказника, вблизи поселка Бухтал, на основе ландшафтного критерия в соответствии с условиями района размещения НПЗ. Отбор производился из прикопок (5 по углам и в центре) и разрезов (3 в пределах площадки).

Таким образом, отбор почв на исследованных территориях Тюменской области осуществлялся из разрезов и прикопок на основе методических рекомендаций $[29,30]$. Мощность горизонтов приведена в табл. 1.

Таблица 1. Строение профиля почв территории Тюменского федерального заказника и района расположения Антипинского нефтеперерабатывающего завода

Table 1. Soil profile structure in the territory of the Tyumen Federal Reserve and in the area of the Antipinsky Oil Refinery

\begin{tabular}{|c|c|c|}
\hline \multirow{2}{*}{$\begin{array}{c}\text { Гори- } \\
\text { зонт } \\
\text { Horizon }\end{array}$} & \multicolumn{2}{|c|}{ Глубина, см/Depth, cm } \\
\cline { 2 - 3 } & Tуüen Federal Reserve & НП3 \\
Antipinsky Oil Refinery \\
\hline A0 & $0-4$ & $0-4$ \\
\hline A1 & $4-12$ & $4-13$ \\
\hline A1A2 & $14-24$ & $13-32$ \\
\hline A2 & $24-52$ & $32-49$ \\
\hline A2B & $52-60$ & $49-70$ \\
\hline B & $60-90$ & $70-85$ \\
\hline BC & - & $85-120$ \\
\hline
\end{tabular}

Общее количество проб почвы - 56, включая 20 для ТФЗ, 36 для Антипинского НПЗ.

Ландшафт исследованного участка ТФЗ представлен березово-сосновым с липой лесом. Район размещения Антипинского НПЗ - природно-техногенная территория радиусом около 2 км от объекта с разной степенью техногенной трансформации. Наиболее преобразован техногенезом участок к северу от завода, протягивающийся до берега реки Туры и представленный урбанизированным районом (поселок Антипино). Территории в восточном и западном направлениях от НПЗ преимущественно урбанизированы, но сохранили участки лиственного леса. К югу находится наименее техногенно трансформированный район. Здесь сохранились участки лиственного, хвойного и смешанного леса с несколькими редко разбросанными техногенными объектами. 
Почвы территорий исследования принадлежат к дерново-подзолистому типу [31]. Ввиду того, что значительная часть территории нахождения НПЗ представлена урбанизированным районом, вызванные этим техногенные изменения привели к распространению урбаноземов. Материнскими породами на изученных территориях являются песчано-аллювиальные отложения, что отразилось в гранулометрическом составе почв преобладанием легких и средних суглинков. Однако подстилающие породы различны: в рассматриваемом районе ТФЗ они представлены верхнеолигоценовыми алевритами и алевристыми глинами туртасской свиты с линзами тонкозернистых песков, в районе НПЗ - средне- и верхнеэоценовыми алевристыми зеленоцветными глинами тавдинской свиты с присыпками и гнездами песков и алевритов, прослоями кварцево-глауконитовых песков и включениями глинистых сидеритов, и нижнеолигоценовыми песками куртамышской свиты с прослоями глин, алевритов, с линзами лигнита и включениями растительных остатков к югу [32].

Содержание химических элементов в почвах было определено методом инструментального нейтронноактивационного анализа. Работы осуществляли с использованием многоканального анализатора импуль-

ТФ3

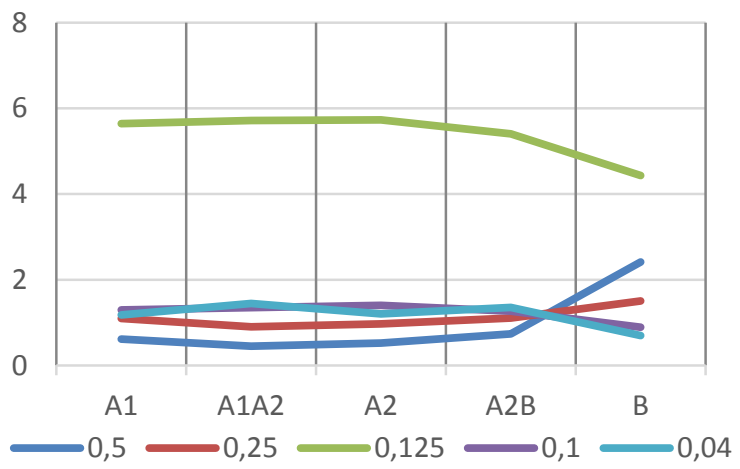

сов AMA 02Ф с полупроводниковым Ge-Li детектором ДГДК-63А в ядерно-геохимической лаборатории ТПУ. Стандартным образцом служил БИЛ-1 [33].

Гранулометрический состав почв определен в соответствии с ГОСТ 12536-2014 путем просеивания через ряд сит: 0,5, 0,25, 0,125, 0,1, 0,04 мм. Содержание магнитной фракции установлено путем выделения ее методом обработки почвы магнитом. Содержание гумуса и рН определено методом Тюрина в соответствии с ГОСТ 26213-91 и методом солевой вытяжки в соответствии с ГОСТ 26483-85.

Статистические показатели вычислялись с использованием пакета анализа Statistika 6.0. Качественные характеристики содержания химических элементов описывает коэффициент концентрации химических элементов (Кк), вычисляемый как отношение содержания химического элемента в конкретной среде к фоновому [34].

\section{Результаты исследования и обсуждение}

В гранулометрическом составе почв изученных территорий наблюдается преобладание фракций, соответствующих тонкому песку, размерностью от 0,04 до 0,125 мм, согласно классификации (Качинский, 1957) (рис. 1).

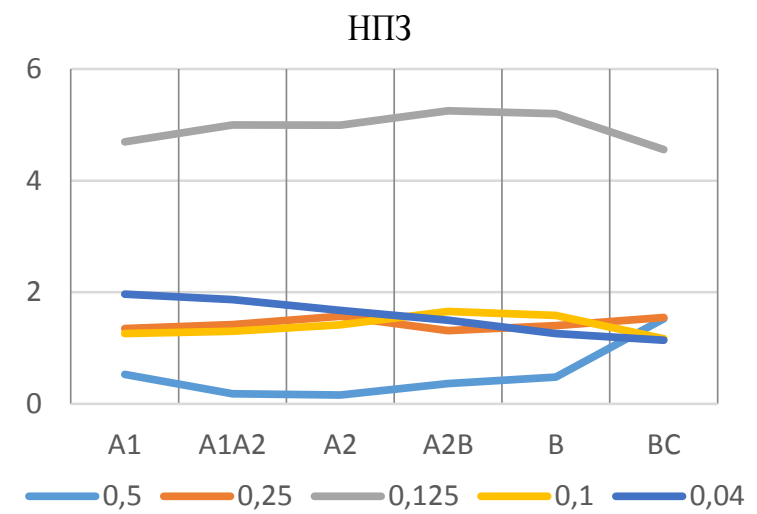

Puc. 1. Распределение фракций по профилю почвы территории Тюменского федерального заказника и территории расположения Антипинского нефтеперерабатывающего завода (2 из 10 г)

Fig. 1. Distribution of fractions along the soil profile in the territory of the Tyumen Federal Reserve and in the territory of the Antipinsky Oil Refinery ( $\mathrm{g} / \mathrm{lO} \mathrm{g}$ )

На территории расположения НПЗ в верхней части профиля больше доля фракции 0,04 мм относительно фракции 0,125 мм (рис. 1), то есть почва здесь имеет более тонкозернистый гранулометрический состав.

Распределение гранулометрических фракций по профилю происходит по близким закономерностям. В большинстве горизонтов оно равномерно, за исключением горизонта В. В нем возрастает доля фракций, соответствующих среднему песку, за счет снижения содержания фракций крупной пыли (рис. 1).

Доля магнитной фракции в почве территории ТФЗ в среднем составляет около $3 \%$ (рис. 2).

Доля магнитной фракции почвы ТФЗ минимальна в горизонте A1A2 и возрастает с глубиной до максимальной в горизонте В (рис. 2).

Для почвы территории расположения НПЗ этот показатель ниже (чуть больше 2,6 \%).
К тому же, в отличие от почвы ТФЗ, наибольшая доля магнитной фракции наблюдается в горизонте A1. В остальной части профиля ее распределение близко к равномерному (рис. 2).

Почва территории ТФЗ характеризуется наибольшим содержанием гумуса в горизонте А2 (рис. 3).

В горизонте А содержание гумуса в почве дерново-подзолистого типа наибольшее (3-7 \%) [35]. На изученной территории выявлены меньшие показатели: максимальное значение наблюдается в горизонте А2 и составляет $2,5 \%$, в остальных горизонтах доля гумуса менее $0,5 \%$.

Показатель $\mathrm{pH}$ в изученной почве также соответствует отмеченному в литературных источниках диапазону от 3,3 до 5,5 [36]. Он возрастает с глубиной примерно от 4,2 в верхней части профиля до 4,44 в нижней. Данная закономерность также отмечена в литературе [37]. 
ТФ3

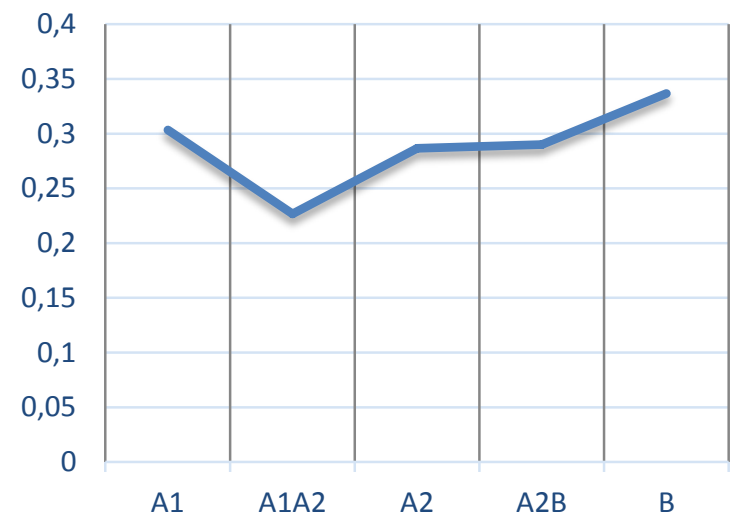

НПЗ

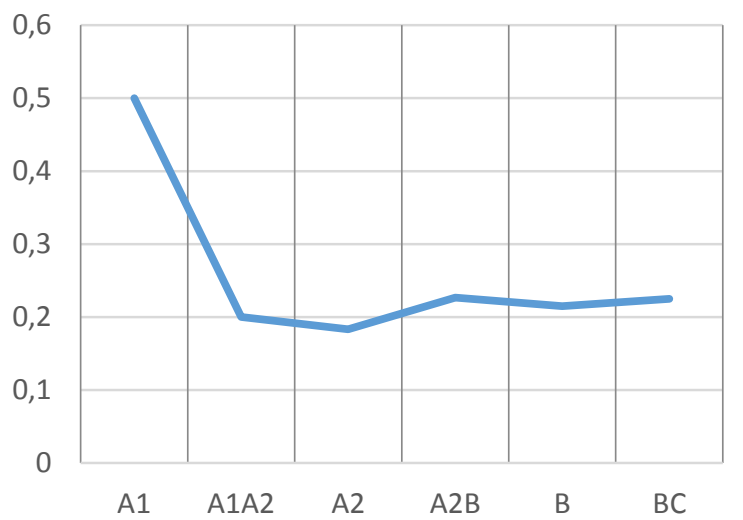

Pис. 2. Распределение магнитной фракиии по профилю почвы территории Тюменского федерального заказника и территории расположения Антипинского нефтеперерабатывающего завода (г из 10 г)

Fig. 2. Distribution of the magnetic fraction along the soil profile in the territory of the Tyumen Federal Reserve and in the territory of the Antipinsky Oil Refinery $(\mathrm{g} / \mathrm{l} 0 \mathrm{~g})$

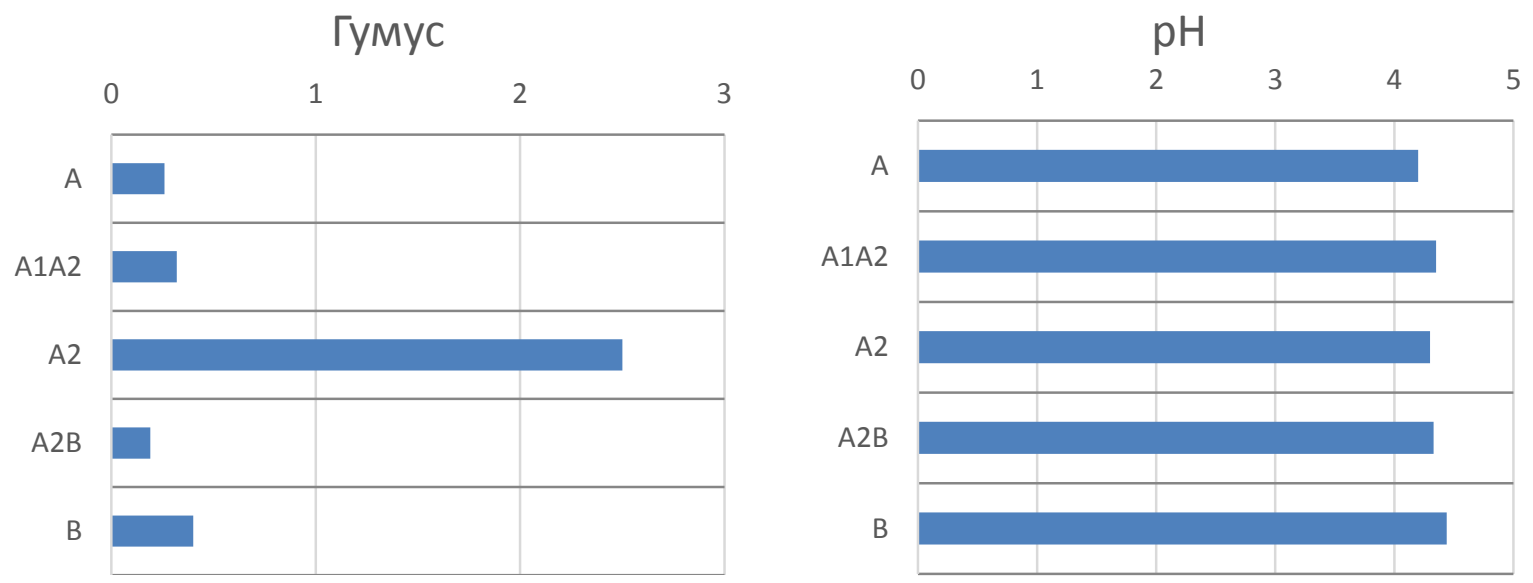

Puc. 3. Содержание гумуса (\%) и рН в почве территории Тюменского федерального заказника

Fig. 3. Humus content (\%) and $\mathrm{pH}$ in the soil of the Tyumen Federal Reserve

Данные по содержанию таких специфических для нефтеперерабатывающей промышленности элементов, как $\mathrm{Zn}, \mathrm{Br}, \mathrm{Sb}, \mathrm{Co}, \mathrm{As}$, представлены в табл. 2.

Таблица 2. Содержание изученных химических элементов в профиле почв рассмотренных территорий (мг/кг)

Table 2. Content of the studied chemical elements in the soil profile of the considered territories $(\mathrm{mg} / \mathrm{kg})$

\begin{tabular}{|c|c|c|c|c|c|c|c|c|c|c|}
\hline \multirow[b]{2}{*}{ 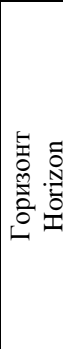 } & \multicolumn{2}{|c|}{$\mathrm{Zn}$} & \multicolumn{2}{|c|}{$\mathrm{Br}$} & \multicolumn{2}{|r|}{$\mathrm{Sb}$} & \multicolumn{2}{|r|}{ As } & \multicolumn{2}{|c|}{ Co } \\
\hline & 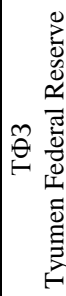 & 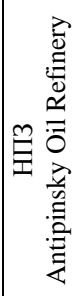 & 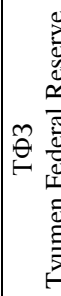 & 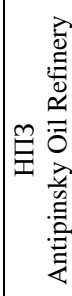 & 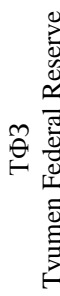 & 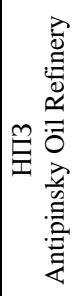 & 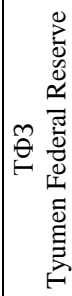 & 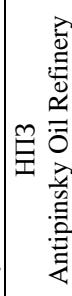 & 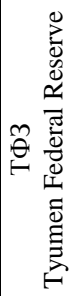 & 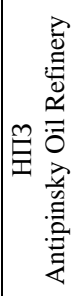 \\
\hline A1 & 14,95 & 18,70 & 0,81 & 1,42 & 0,25 & 0,38 & 1,37 & 1,43 & 4,70 & 6,74 \\
\hline $\mathrm{A} 1 \mathrm{~A} 2$ & 5,47 & 12,30 & 0,61 & 0,65 & 0,17 & 0,21 & 0,58 & 0,27 & 3,58 & 2,47 \\
\hline A2 & 9,20 & 6,93 & 0,52 & 0,50 & 0,18 & 0,14 & 0,97 & 0,73 & 4,59 & 2,61 \\
\hline A2B & 7,60 & 10,70 & 0,44 & 0,44 & 0,22 & 0,20 & 0,91 & 0,65 & 6 & 2,86 \\
\hline B & 18,53 & 9,50 & 0,82 & 0,59 & 0,27 & 0,17 & 2,31 & 0,76 & 7,22 & 2,83 \\
\hline BC & - & 6,15 & - & 0,70 & - & 0,30 & - & 1,04 & - & 3,71 \\
\hline
\end{tabular}

Содержание их в верхнем горизонте почвы территории ТФЗ ниже кларковых значений (табл. 3).

Таблица 3. Геохимические ряды для верхнего горизонта почв изученных территорий относительно кларка (Ярошевский, 1990)

Table 3. Geochemical series for the upper soil horizon of the studied territories relative to the clarke

\begin{tabular}{|c|l|}
\hline $\begin{array}{c}\text { ТФЗ/кларк } \\
\text { Tyumen Federal Reserve/clarke }\end{array}$ & $\mathrm{Co}_{0,52}>\mathrm{Sb}_{0,28}>\mathrm{Zn}_{0,25}>\mathrm{As}_{0,23}>\mathrm{Br}_{0,02}$ \\
\hline $\begin{array}{c}\text { НПЗ/кларк } \\
\text { Antipinsky Oil Refinery/clarke }\end{array}$ & $\mathrm{Co}_{0,79}>\mathrm{Sb}_{0,44}>\mathrm{Zn}_{0,3}>\mathrm{As}_{0,26}>\mathrm{Br}_{0,045}$ \\
\hline
\end{tabular}

Это актуально и для горизонта A1 почвы района расположения НПЗ, хотя здесь выше коэффициенты концентрации. Это отражает невысокую техногенную нагруженность территории расположения предприятия за относительно непродолжительный срок его функционирования.

Техногенная измененность этой территории проявляется при сопоставлении ее с территорией ТФЗ. Это выявляет повышенные содержания всех рассматриваемых элементов в почве, подверженной воздействию НПЗ (рис. 4). 


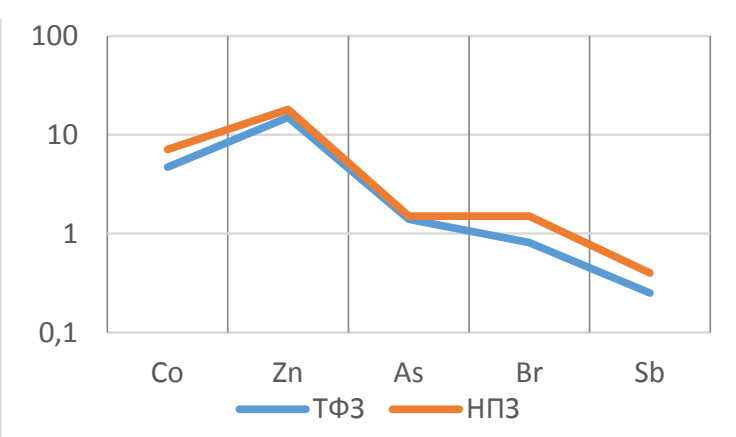

Pис. 4. Содержание химических элементов в горизонте А1 почвы территории расположения Антипинского нефтеперерабатывающего завода в сравнении с Тюменским федеральным заказником (мг/кг, логарифмическая шкала)

Fig. 4. Content of chemical elements in the Al horizon of the soil in the territory of the Antipinsky Oil Refinery in comparison with the Tyumen Federal Reserve ( $\mathrm{mg} / \mathrm{kg}$, logarithmic scale)

Сравнение данных по этим элементам для изученных территорий по горизонтам отражает техногенное их поступление в почву района размещения НПЗ с атмосферными выпадениями, о чем свидетельствуют наибольшие коэффициенты концентрации в горизонте A1 и их сокращение книзу (табл. 4).

Исключение составляет Zn. В отличие от прочих рассмотренных элементов, наибольший коэффициент концентрации наблюдается для него в горизонте A1A2. К тому же проявляется повышенное его накопление в нижней части профиля, в горизонте A2B.

Таблица 4. Геохимические ряды для профиля почвы территории расположения Антипинского нефтеперерабатывающего завода относительно Тюменского федерального заказника

Table 4. Geochemical series for the soil profile in the territory of the Antipinsky Oil Refinery in relation to the Tyumen Federal Reserve

\begin{tabular}{|c|c|}
\hline $\mathrm{A} 1$ & $\mathbf{B r}_{1,7}>\mathbf{S b}_{\mathbf{1 , 5}}>\mathbf{C o}_{\mathbf{1 , 4}}>\mathbf{Z n}_{\mathbf{1 , 2}}>\mathbf{A s}_{\mathbf{1}}$ \\
\hline $\mathrm{A} 1 \mathrm{~A} 2$ & $\mathbf{Z n}_{2,3}>\mathbf{S b}_{\mathbf{1 , 3}}>\mathbf{B r}_{1, \mathbf{1}}>\mathrm{Co}_{0,69}>\mathrm{As}_{0,46}$ \\
\hline $\mathrm{A} 2$ & $\mathrm{Br}_{0,95}>\mathrm{Sb}_{0,76}>\mathrm{Zn}_{0,75}>\mathrm{As}_{0,75}>\mathrm{Co}_{0,57}$ \\
\hline $\mathrm{A} 2 \mathrm{~B}$ & $\mathbf{Z n}_{\mathbf{1 , 4}}>\mathrm{Br}_{0,98}>\mathrm{Sb}_{0,92}>\mathrm{As}_{0,71}>\mathrm{Co}_{0,48}$ \\
\hline $\mathrm{B}$ & $\mathrm{Br}_{0,72}>\mathrm{Sb}_{0,64}>\mathrm{Zn}_{0,51}>\mathrm{Co}_{0,39}>\mathrm{As}_{0,33}$ \\
\hline
\end{tabular}

Примечание: жирным выделены элементы с Кк $\geq 1$.

Note: elements with concentration coefficient $\geq 1$ are marked in bold.

В горизонте A1A2, помимо Zn, повышенные коэффициенты концентрации сохраняют $\mathrm{Br}$ и $\mathrm{Sb}$. Co и $\mathrm{As}$ содержатся в повышенных количествах только в A1.

Сопоставление распределения рассматриваемых элементов по профилю свидетельствует об изменении этих закономерностей в почве района расположения НПЗ относительно территории ТФЗ.

Так, в почве территории ТФЗ Zn проявляет преимущественное накопление в горизонтах В и A1. В почве района влияния НПЗ наибольшее накопление характерно для горизонта A1, большее, чем в первом случае. Книзу наблюдается сокращение концентрации (рис. 5).
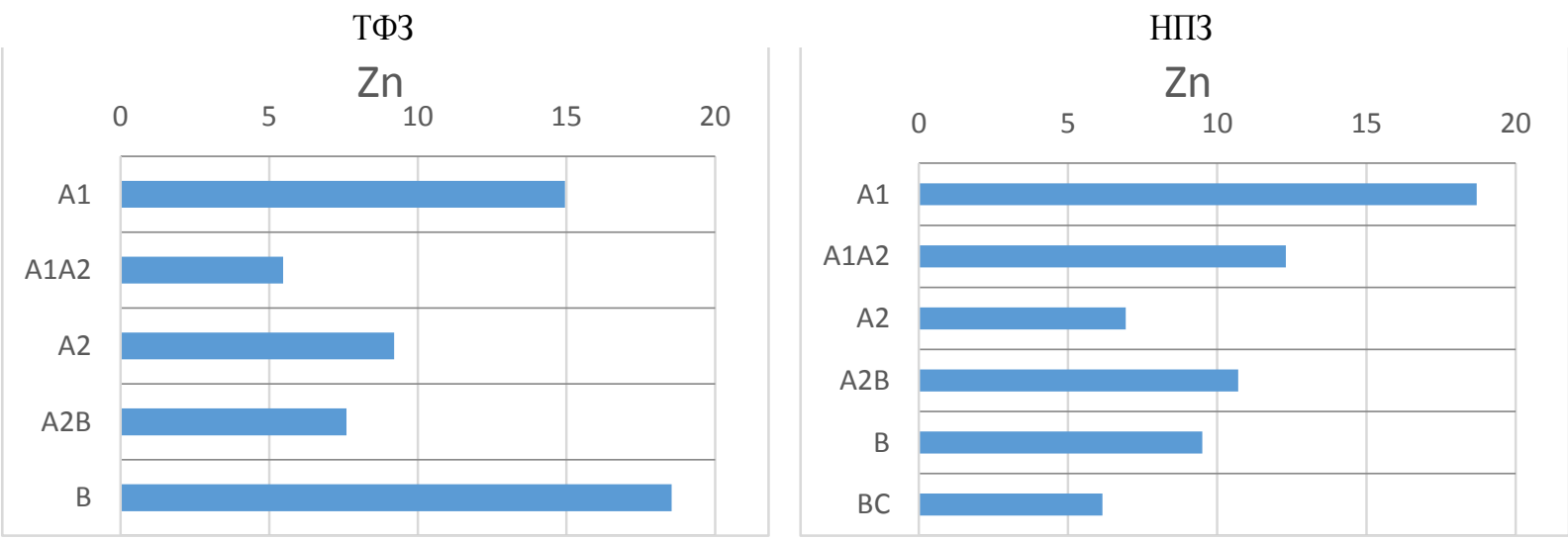

Pис. 5. Содержание Zn в профиле почв Тюменского федерального заказника и Антипинского нефтеперерабатываюмего завода (мг/кг)

Fig. 5. Zn content in the soil profile of the Tyumen Federal Reserve and Antipinsky Oil Refinery (mg/kg)

В соответствии с литературными данными для $\mathrm{Zn}$ в дерново-подзолистых почвах характерно возрастание содержания с глубиной [38], что отчасти проявляется в почве ТФЗ. Это обусловлено удержанием этого элемента глинистой фракцией и соединениями $\mathrm{Fe}[39,40]$. Накопление в верхнем горизонте объясняется удержанием Zn органическим веществом в виде гуминовых и фульвокислот [41].

$\mathrm{Br}$ на фоновой территории ТФЗ проявляет наибольшее, почти равноценное, накопление в горизонтах A1 и В. В целом наблюдается сокращение содержания книзу. В почве территории НПЗ сохраня- ются сходные закономерности распределения по профилю за исключением значительного повышения содержания в горизонте A1 (рис. 6).

Накопление $\mathrm{Br}$ в верхнем горизонте считается характерным и объясняется атмосферным выпадением ввиду высокой летучести [42].

Для $\mathrm{Sb}$ характерно возрастание содержания книзу в почве ТФЗ. Наибольшее накопление наблюдается в горизонте В, чуть меньшее - в А1. В почве района расположения ТФЗ нарушаются общие фоновые закономерности распределения, значительно возрастает содержание элемента в горизонте A1 (рис. 7). 


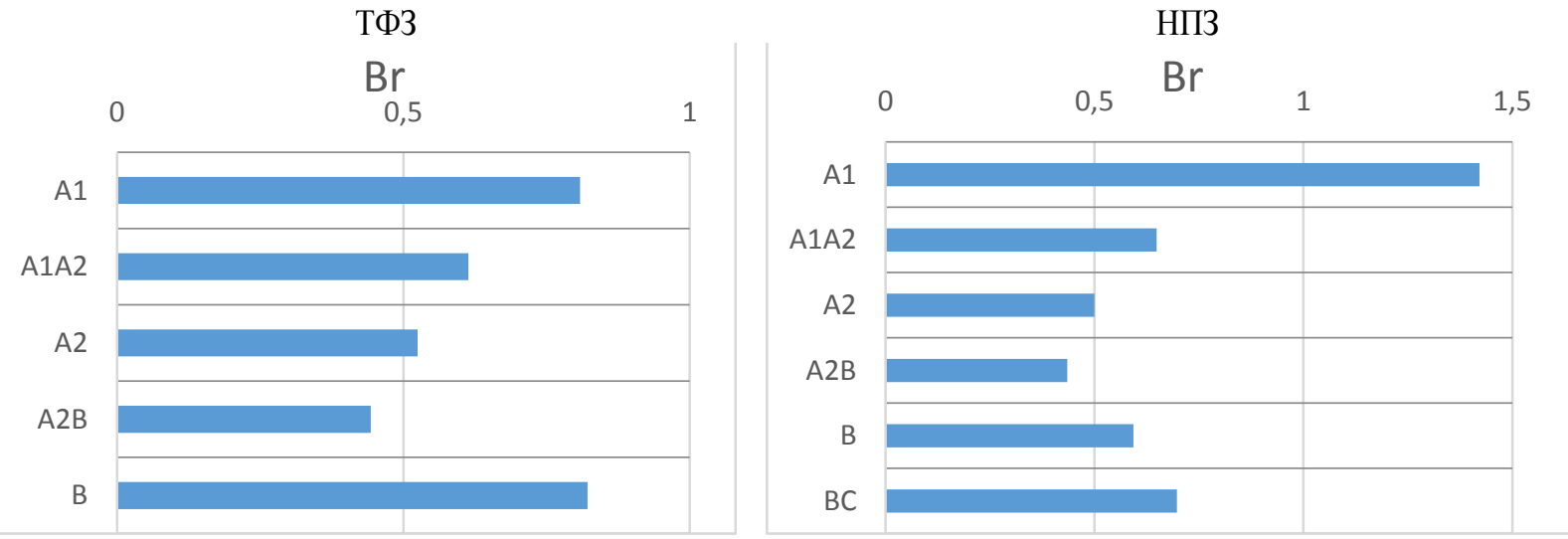

Pис. 6. Содержание Вr в профиле почв Тюменского федерального заказника и Антипинского нефтеперерабатывающего завода (мг/кг)

Fig. 6. Br content in the soil profile of the Tyumen Federal Reserve and Antipinsky Oil Refinery (mg/kg)

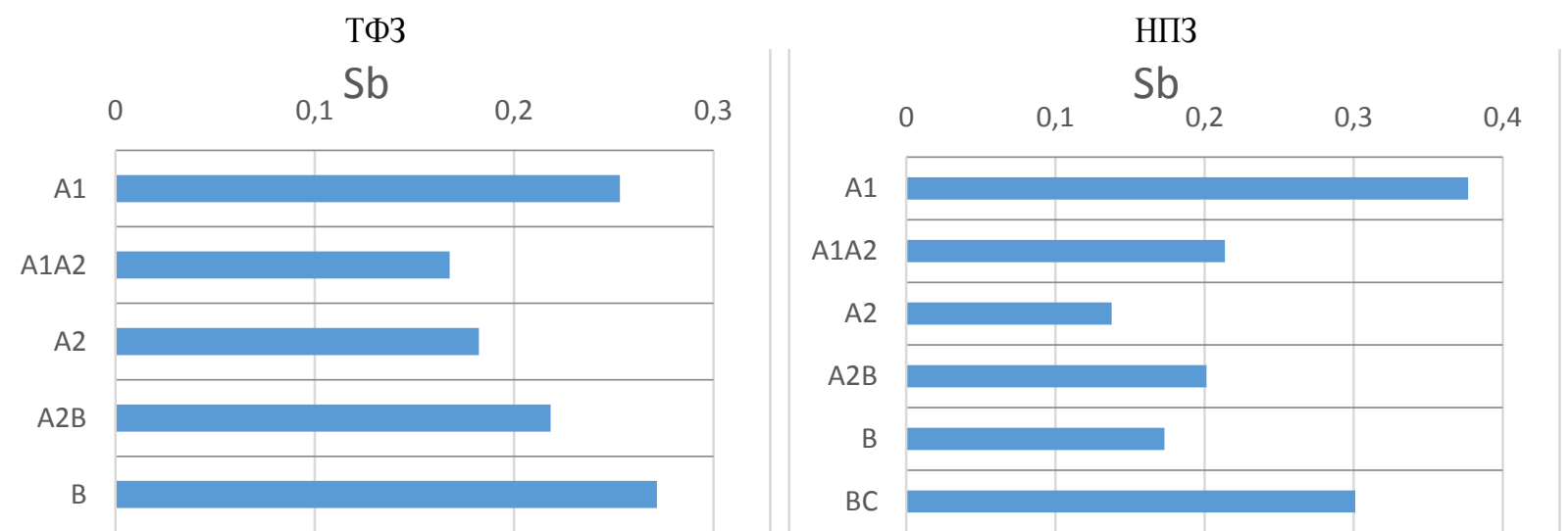

Pис. 7. Содержание Sb в профиле почв Тюменского федерального заказника и Антипинского нефтеперерабатывающего завода (мг/кг)

Fig. 7. Sb content in the soil profile of the Tyumen Federal Reserve and Antipinsky Oil Refinery (mg/kg)

Характер распределения $\mathrm{Sb}$ по разрезу определяется удержанием данного элемента гидроксидами железа [39, 40], органическим веществом [43], глинистыми минералами [44].

Аналогичная ситуация наблюдается для Со. В почве ТФЗ проявляется схожее распределение с возрастанием содержания книзу. Под техногенной нагрузкой НПЗ также существенно повышается накопление в горизонте A1. В остальной части профиля содержание сокращается (рис. 8).

Сидерофильный Со близок по закономерностям распределения к Fe: вынос из горизонта A1A2 и повышение содержания книзу. Но для Со наблюдаются большие различия в содержании между верхней и средней частями профиля. Такой характер распределения обусловлен поступлением этих элементов в почвы из материнских пород [42, 36].

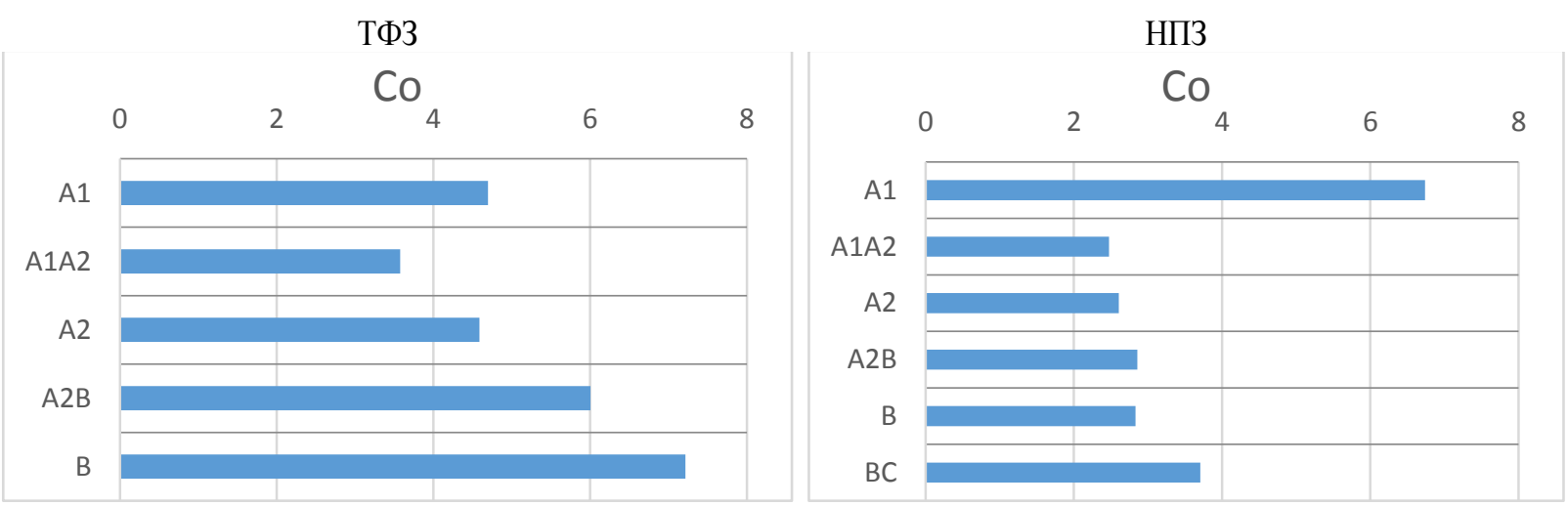

Pис. 8. Содержание Со в профиле почв Тюменского федерального заказника и Антипинского нефтеперерабатывающего завода (мг/кг)

Fig. 8. Co content in the soil profile of the Tyumen Federal Reserve and Antipinsky Oil Refinery (mg/kg) 
Для Аs в почве ТФЗ характерно преимущественное накопление в горизонте В. Также наблюдается накопление в горизонте А1. В почве района расположения ТФЗ в А1 сохраняется близкое содержание, но в остальной части профиля оно значительно ниже, особенно в В. Вследствие этого преимущественное накопление здесь характерно для А1 (рис. 9).
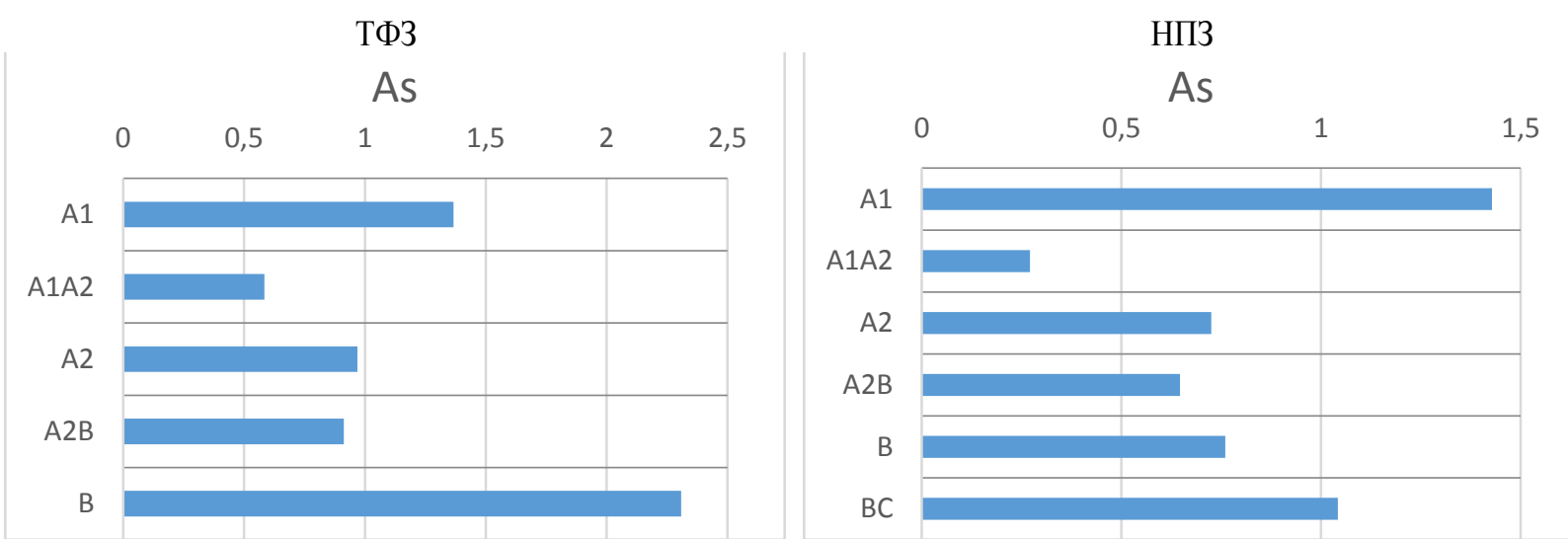

Pис. 9. Содержание As в профиле почв Тюменского федерального заказника и Антипинского нефтеперерабатывающего завода (мг/кг)

Fig. 9. As content in the soil profile of the Tyumen Federal Reserve and Antipinsky Oil Refinery ( $\mathrm{mg} / \mathrm{kg})$

As имеет близкий характер распределения к $\mathrm{Fe}$, что обусловлено сродством к нему [39, 42, 43]. Повышенное содержание в горизонте В по отношению к А наблюдается в подзолистых почвах других регионов [42].

Таким образом, халькофильные $\mathrm{As}, \mathrm{Zn}$ и $\mathrm{Sb}$ аналогичны по закономерностям распределения, но $\mathrm{Zn}$ больше накапливается в $\mathrm{A} 1$ и $\mathrm{A} 2, \mathrm{a} \mathrm{Sb}$ - в A1 и A2B, ввиду чего содержание последней равномерно повышается книзу.

\section{Выводы}

1. В почвах исследованных территорий содержание рассмотренных элементов ниже кларка.

\section{СПИСОК ЛИТЕРАТУРЬ}

1. Соломонов А.П. Развитие мировой нефтепереработки под влиянием структурных изменений в топливно-энергетическом балансе // Вестник евразийской науки. - 2019. - № 6. URL: https://esj.today/PDF/33ECVN619.pdf (дата обращения 12.01.2021)

2. Барагинский О.Б. Нефтегазовый комплекс мира. - М.: Изд-во «Нефть и газ» РГУ нефти и газа им. И.М. Губкина, 2006. $640 \mathrm{c}$.

3. Нефтеперерабатывающие заводы России // ПроНПЗ. URL: https://pronpz.ru/neftepererabatyvayushchie-zavody/rossiya.html (дата обращения 12.01.2021).

4. Лобачева А.А. Влияние ОАО «Куйбышевский нефтеперерабатывающий завод» на почвенный и растительный покров прилегающих территорий: дис. ... канд. биол. наук. - Самара. 2010. $-225 \mathrm{c}$.

5. Simulating behavior of petroleum compounds during refinery effluent treatment using the SimpleTreat model / N.W. Thunnissen, D. van de Meent, J. Struijs, M. Hjort, A.D. Redman, M.G.D. Smit, A.J. Hendriks, R. van Zelm // Chemosphere. - 2021. - V. 263. 128081. URL: https://doi.org/10.1016/j.chemosphere.2020.128081 (дата обращения 12.01.2021).

6. Development of low-cost activated carbon towards an ecoefficient removal of organic pollutants from oily wastewater / R. Remmani, R. Makhloufi, M. Miladi, A. Ouakouak, A.R. Canales, D. Núñez-Gómez // Polish Journal of Environmental Studies. - 2021. - V. 30. - № 2. - P. 1801-1808. URL: https://doi.org/10.15244/pjoes/125765 (дата обращения 12.01.2021)
2. Верхний горизонт почвы района размещения Антипинского нефтеперерабатыващего завода отличается от почвы территории Тюменского федерального заказника повышенным содержанием рассмотренных химических элементов.

3. В районе деятельности Антипинского нефтеперерабатыващего завода наблюдается изменение закономерностей содержания данных элементов по профилю с увеличением накопления в горизонте A1.

Подготовка статьи осуществлялась при поддержке гранта РНФ 20-64-47021.

7. Photocatalytic oxidative degradation of hydrocarbon pollutants in refinery wastewater using TiO2 as catalyst / I. Ul haq, W. Ahmad, I. Ahmad, M. Yaseen // Water Environment Research. - 2020. V. 92. - № 12. - P. 2086-2094. URL: https://doi.org/10.1002/ wer.1370 (дата обращения 12.01.2021).

8. Tetteh E.K., Rathilal S., Naidoo D.B. Photocatalytic degradation of oily waste and phenol from a local South Africa oil refinery wastewater using response methodology // Scientific Reports. 2020. - V. 10. - 8850. URL: https://doi.org/10.1038/s41598-02065480-5 (дата обращения 12.01.2021).

9. Emissions of volatile organic compounds from crude oil processing - Global emission inventory and environmental release. / H. Rajabi, M.H. Mosleh, P. Mandal, A.R. Lea-Langton, M. Sedighi // Science of the Total Environment. - 2020. - V. 727. 138654. URL: https://doi.org/10.1016/j.scitotenv.2020.138654 (дата обращения 12.01.2021).

10. Tarafdar A., Sinha A. Public health risk assessment with bioaccessibility considerations for soil PAHs at oil refinery vicinity areas in India // Science of The Total Environment. 2018. - V. 616. - P. 1477-1484.

11. Alharbi B.H., Pasha M.J., Al-Shamsi M.A.S. Influence of different urban structures on metal contamination in two metropolitan cities. - 2019. URL: https://doi.org/10.1038/s41598-019-40180-x (дата обращения 12.01.2021)

12. Epstein A.C. The human health implications of oil and natural gas development // Environmental Issues Concerning Hydraulic Fracturing. - 2017. - V. 1. - P. 113-145.

13. Brockmeyer S., D'Angiulli A. How air pollution alters brain development: the role of neuroinflammation // Translational Neuroscience. - 2016. - № 7 (1). - P. 24-30. 
14. Heavy metal pollution of oil-based drill cuttings at a shale gas drilling field in Chongqing, China: a human health risk assessment for the workers / T. Xu, L. Wang, X. Wang, T. Li, X. Zhan // Ecotoxicology and Environmental Safety. - 2018. - № 165 P. $160-163$.

15. Numerical analysis of frozen soil around the Mohe-Daqing crude oil pipeline with thermosyphons / L. Fang, B. Yu, J. Li, Y. Zhao, G. Yu, W. Zhao // Heat Transfer Engineering. - 2018. - V. 39. № 7-8. - P. 630-641.

16. Kuang S., Lang Q., Yu W. Effects of aged oil sludge on soil physicochemical properties and fungal diversity revealed by highthroughput sequencing analysis // Archaea in Wastewater Treatment: Current Research and Emerging Technology. - 2018. V. 2018. - 9264259. URL: https://doi.org/10.1155/2018/9264259 (дата обращения 12.01.2021).

17. Unitary and binary remediations by plant and microorganism on refining oil-contaminated soil / J.J. Fei, Y.Y. Wan, X.Y. He, Z.H. Zhang, X.Y. Yu // Environmental Science and Pollution Research. - 2020. - V. 27. - 41253-41264. URL https://doi.org/10.1007/s11356-020-10025-6 (дата обращения 12.01.2021).

18. Hatami E., Abbaspour A., Dorostkar V. Phytoremediation of a petroleum-polluted soil by native plant species in Lorestan Province, Iran // Environmental Science and Pollution Research. 2019. - V. 26. - 24323-24330. URL: https://doi.org/10.1007/ s11356-018-1297-7 (дата обращения 12.01.2021).

19. Rhizoremediation of petroleum hydrocarbon-contaminated soils: improvement opportunities and field applications / I. Hussain, M. Puschenreiter, S. Gerhard, P. Schöftner, S. Yousaf, A. Wang, J.H. Syed, T.G. Reichenauer // Environmental and Experimental Botany. - 2018. - V. 147. - P. 202-219. URL: https://doi.org/ 10.1016/j.envexpbot.2017.12.016 (дата обращения 12.01.2021).

20. O'Brien P.L., Desutter T.M., Casey F.X.M. Natural degradation of low-level petroleum hydrocarbon contamination under crop management // Journal of Soils and Sediments. - 2019. - V. 19. P. 1367-1373. URL: https://doi.org/10.1007/s11368-018-2153-6 (дата обращения 12.01.2021).

21. Jafarinejad, S., Jiang S.C. Current technologies and future directions for treating petroleum refineries and petrochemical plants (PRPP) wastewaters // Journal of Environmental Chemical Engineering. - 2019. - V. 7. - № 5. - 103326. URL: https://doi.org/10.1016/j.jece.2019.103326 (дата обращения 12.01.2021)

22. Летувнинкас А.И. Антропогенные геохимические аномалии и природная среда. 2-е изд., доп. и испр. - Томск: Изд-во НТЛ, 2005. $-290 \mathrm{c}$.

23. Абросимов А.А. Экология переработки углеводородных систем / под ред. д-ра хим. наук, проф. М.Ю. Доломатова, д-ра техн. наук, проф. Э.Г. Теляшева. - М.: Химия, 2002. -608 с.

24. A characterization of the soils and sediments in contaminated sites and rivers using petroleum biomarker compounds / N.-H. Kao, M.-C. Su, C.-C. Yen, Y.-J. Huang // Journal of Soils and Sediments. - 2019. - № 19. - P. 241-254.

25. Опекунова М.Г. Биоиндикация загрязнений. - СПб.: Изд-во С.-Петербургского университета, 2004. - 266 c.

26. Изменение элементного состава верхнего горизонта почв под воздействием предприятий нефтегазопереработки / В.В. Боев, Н.В. Барановская, В.А. Боев, М.Т. Джамбаев, Т.С. Шахова, Л.В. Жорняк // Известия Томского политехнического универ- ситета. Инжиниринг георесурсов. - 2019. - Т. 330. - № 11 C. $179-191$

27. Охрана природы. Почвы. Общие требования к отбору проб: межгосударственный стандарт ГОСТ 17.4.3.01-2017: введен 01.01.19. - М.: Стандартинформ, 2018. - 4 c.

28. Методы изучения лесных сообществ / под ред. Ярмишко В.Т., Лянгузовой И.В. - СПб.: НИИХимии СПбГУ, 2002. - 240 с.

29. Розанов Б.Г. Морфология почв. - М.: Академический проект, 2004. $-432 \mathrm{c}$

30. Фомин Г.С., Фомин А.Г. Почва. Контроль качества и экологической безопасности по международным стандартам. Справочник. - М.: Госстандарт России, 2001. - 300 с.

31. Полевой определитель почв / под ред. Острикова К.Т. - М.: Почвенный ин-т им. В.В. Докучаева, 2008. - 182 с.

32. Геологическая карта Тюменской области (южные районы). Масштаб 1:2500000. URL: http://www.vsegei.ru/ru/info/gisatlas/ ufo/tyumenskaya_obl/ (дата обращения 12.01.2021).

33. Судыко А.Ф. Определение урана, тория, скандия и некоторых редкоземельных элементов в двадцати четырех стандартных образцах сравнения инструментальным нейтронноактивационным методом // Радиоактивность и радиоактивные элементы в среде обитания человека: Материалы V Международной конференции. - Томск, 2016. - С. 620-624.

34. Ревич Б.А., Сает Ю.Е., Смирнова Р.С. Методические рекомендации по оценке степени загрязнения атмосферного воздуха населенных пунктов металлами по их содержанию в снежном покрове и почве (Утв. 15 мая 1990 г. № 5174-90). М.: ИМГРЭ, 1990. - $16 \mathrm{c}$.

35. Почвоведение. В 2 ч. Ч. 2. Типы почв, их география и использование / Л.Г. Богатырев, В.Д. Васильевская, А.С. Владыченский и др. - М.: Высш. шк., 1988. - 368 с.

36. Каретин Л.Н. Почвы Тюменской области. - Новосибирск: Наука, Сиб. отделение, 1990. - 286 с.

37. Горшенкин К.П. Почвы южной части Сибири. - М.: Изд-во AH CCCP, 1955. - $592 \mathrm{c}$.

38. Безносиков В.А., Лодыгин Е.Д., Кондратенок Б.М. Оценка фонового содержания тяжелых металлов в почвах европейского северо-востока России // Почвоведение. - 2007. - № 9. C. $1064-1070$.

39. Водяницкий Ю.Н. Роль соединений железа в закреплении тяжелых металлов и металлоидов в почвах (обзор литературы) // Почвоведение. - 2010. - № 5. - С. 558-572.

40. Manceau A., Marcus M.A., Tamura N. Quantitative speciation of heavy metals in soils and sediments by synchrotron X-ray techniques // Applications of Synchrotron Radiation in LowTemperature Geochemistry and Environmental Science. Reviews in Mineralogy and Geochemistry. - 2002. - V. 49. - P. 341-428.

41. Саенко Г.Н. Металлы и галогены в морских организмах. - М.: Наука, 1992. - $200 \mathrm{c}$.

42. Иванов В.В. Экологическая геохимия элементов: Справочник: в 6 кн. / под ред. Э.К. Буренкова. - М.: Недра, 1994. - 2558 с.

43. Role of sediment composition in trace metal distribution in lake sediments / L. El Bilali, P.E. Rasmussen, G.E.M. Hall, D. Fortin // Applied Geochemistry. - 2002. - V. 17. - P. 1171-1181.

44. Leuz A.-K., Monch H., Johnson C.A. Sorption of Sb (III) and Sb (V) to goethite: Influence on $\mathrm{Sb}$ (III) oxidation and mobilization /I Environmental Science \& Technology. - 2006. - V. 40. - P. 7277-7282.

Поступила 13.10.2021 2.

\section{Информация об авторах}

Боев В.B., кандидат геолого-минералогических наук, ассистент кафедры геоэкологии Тюменского государственного университета.

Барановская Н.B., доктор биологических наук, профессор отделения геологии Инженерной школы природных ресурсов Национального исследовательского Томского политехнического университета.

Боев B.A., кандидат биологических наук, доцент кафедры геоэкологии Тюменского государственного университета. 
UDC 550.424.2:665.6

\title{
CHANGE OF MIGRATION OF CHEMICAL ELEMENTS IN THE AREA OF LOCATION OF THE PETROLEUM REFINING PLANT
}

\author{
Vladislav V. Boev 1 , \\ v.-3@mail.ru
}

\section{Natalya V. Baranovskaya ${ }^{2}$,} natalya.baranovs@mail.ru

\author{
Viktor A. Boev ${ }^{1}$, \\ vikboev2009@mail.ru \\ 1 Tyumen State University, \\ 6, Volodarsky street, Tyumen, 625003, Russia. \\ 2 National Research Tomsk Polytechnic University, \\ 30, Lenin avenue, Tomsk, 634050, Russia.
}

The relevance of the research is caused by the lack of data on the impact of many oil refineries on adjacent soils for specific regions, determined by design and technological features, while the general geochemical specifics of the oil refining industry are studied. The main aim of the research is to identify the features of accumulation in soils and distribution along the profile of some chemical elements specific to the oil refining industry in the area of operation of a relatively new oil refinery by comparing them with data for a background area with similar natural conditions and clarke.

Objects of the research are soils of the Tyumen Federal Reserve and the territory of the location of Antipinsky Oil Refinery.

Methods: selection and preparation of test plots and soils, determination of the elemental composition by instrumental neutron activation and atomic absorption methods, interpretation of results.

Results. The content of Br, Sb, Zn, As, Co in the soils of the eastern part of the Tyumen Federal Reserve and the area of the Antipinsky Oil Refinery, and their distribution along the profile were studied. By comparing the results obtained, an increased content of these chemical elements in the A1 horizon of the soils of the territory where the Antipinsky Oil Refinery is located relative to the Tyumen Federal Reserve and a change in the patterns of their distribution along the profile were revealed. In the soil of the region near the technogenic object, the increased content of the considered chemical elements decreases from top to bottom, which is observed both in absolute values and in concentration coefficients relative to the conditional background data of the soils of the Tyumen Federal Reserve. This indicates the arrival of these elements from the surface. At the same time, in both territories, the content of chemical elements is lower than the clarke, which reflects a relatively low technogenic load in these areas.

\section{Key words:}

Soils elemental composition, Tyumen Federal Reserve, Antipinsky Oil Refinery, technogenic impact of oil refining on soils, technogenic transformation of soils.

The research was supported by the RSF grant 20-64-47021.

\section{REFERENCES}

1. Solomonov A.P. Development of world oil processing under the influence of structural changes in fuel and energy balance. The Eurasian Scientific Journal, 2019, vol. 6 (11). In Rus. Available at: https://esj.today/PDF/33ECVN619.pdf (accessed 12 January 2021)

2. Baraginskiy O.B. Neftegazovy kompleks mira [Oil and gas complex of the world]. Moscow, «Neft i gaz» RGU nefti i gaza im. I.M. Gubkina Publ., 2006. 640 p.

3. Neftepererabatyvayushhie zavody Rossii [Oil refineries in Russia] Available at: https:/pronpz.ru/neftepererabatyvayushchiezavody/rossiya.html (accessed 12 January 2021).

4. Lobacheva A.A. Vliyanie OAO «Kuybyshevskiy neftepererabatyvayushchiy zavod» na pochvenny i rastitelny pokrov prilegayushchikh territoriy. Dis. Kand. nauk [The influence of Kuibyshev Refinery OJSC on soil and plant cover of the adjacent territories. Cand. Diss.]. Samara, 2010. 225 p.

5. Thunnissen N.W., Van de Meent D., Struijs J., Hjort M., Redman A.D., Smit M.G.D., Hendriks A.J., Van Zelm R. Simulating behavior of petroleum compounds during refinery effluent treatment using the SimpleTreat model. Chemosphere, 2021, vol. 263, 128081. Available at: https://doi.org/10.1016/.chemosphere.2020.128081 (accessed 12 January 2021).

6. Remmani R., Makhloufi R., Miladi M., Ouakouak A., Canales A.R., Núñez-Gómez D. Develpment of low-cost activated carbon towards an eco-efficient removal of organic pollutants from oily wastewater. Polish Journal of Environmental Studies, 2021, vol. 30, no. 2, pp. 1801-1808. Available at: https://doi.org/ 10.15244/pjoes/125765 (accessed 12 January 2021).

7. Ul haq I., Ahmad W., Ahmad I., Yaseen M. Photocatalytic oxidative degradation of hydrocarbon pollutants in refinery wastewater using $\mathrm{TiO}_{2}$ as catalyst. Water Environment Research, 2020, vol. 92 , no. 12, pp. 2086-2094. Available at: https://doi.org/10.1002/ wer.1370 (accessed 12 January 2021).

8. Tetteh E.K., Rathilal S., Naidoo D.B. Photocatalytic degradation of oily waste and phenol from a local South Africa oil refinery wastewater using response methodology. Scientific Report, 2020, vol. 10, 8850. Available at: https://doi.org/10.1038/s41598-02065480-5 (accessed 12 January 2021).

9. Rajabi H., Mosleh M.H., Mandal P., Lea-Langton A.R., Sedighi M. Emissions of volatile organic compounds from crude oil processing - global emission inventory and environmental release. Science of the Total Environment, 2020, vol. 727, 138654. Available at: https://doi.org/10.1016/j.scitotenv.2020.138654 (accessed 12 January 2021)

10. Tarafdar A., Sinha A. Public health risk assessment with bioaccessibility considerations for soil PAHs at oil refinery vicinity areas in India. Science of the Total Environment, 2018, vol. 616, pp. 1477-1484.

11. Alharbi B.H., Pasha M.J., Al-Shamsi M.A.S. Influence of Different Urban Structures on Metal Contamination in Two Metropolitan Cities. 2019. Available at: https://doi.org/10.1038/s41598-01940180-x (accessed 12 January 2021). 
12. Epstein A.C. The human health implications of oil and natural gas development. Environmental Issues Concerning Hydraulic Fracturing, 2017, vol. 1, pp. 113-145.

13. Brockmeyer S., D'Angiulli A. How air pollution alters brain development: the role of neuroinflammation. Translational Neuroscience, 2016, no. 7 (1), pp. 24-30.

14. Xu T., Wang L., Wang X., Li T., Zhan X. Heavy metal pollution of oil-based drill cuttings at a shale gas drilling field in Chongqing, China: a human health risk assessment for the workers. Ecotoxicology and Environmental Safety, 2018, no. 165, pp. 160-163.

15. Fang L., Yu B., Li J., Zhao Y., Yu G., Zhao W. Numerical analysis of frozen soil around the Mohe-Daqing crude oil pipeline with thermosyphons. Heat Transfer Engineering, 2018, vol. 39, no. 7-8, pp. 630-641.

16. Kuang S., Lang Q., Yu W. Effects of aged oil sludge on soil physicochemical properties and fungal diversity revealed by highthroughput sequencing analysis. Archaea in Wastewater Treatment: Current Research and Emerging Technology, 2018, vol. 2018, 9264259. Available at: https://doi.org/10.1155/2018/9264259 (accessed 12 January 2021).

17. Fei J.J., Wan Y.Y., He X.Y., Zhang Z.H., Yu X.Y. Unitary and binary remediations by plant and microorganism on refining oilcontaminated soil. Environmental Science and Pollution Research, 2020, vol. 27, 41253-41264. Available at: https://doi.org/10.1007/ s11356-020-10025-6 (accessed 12 January 2021).

18. Hatami E., Abbaspour A., Dorostkar V. Phytoremediation of a petroleum-polluted soil by native plant species in Lorestan Province, Iran. Environmental Science and Pollution Research, 2019, vol. 26, 24323-24330. Available at: https://doi.org/10.1007/s11356-0181297-7 (accessed 12 January 2021).

19. Hussain I., Puschenreiter M., Gerhard S., Schöftner P., Yousaf S., Wang A., Syed J.H., Reichenauer T.G. Rhizoremediation of petroleum hydrocarbon-contaminated soils: improvement opportunities and field applications. Environmental and Experimental Botany 2018, vol. 147, pp. 202-219. Available at: https://doi.org/ 10.1016/j.envexpbot.2017.12.016 (accessed 12 January 2021).

20. O'Brien P.L., Desutter T.M., Casey F.X.M. Natural degradation of lowlevel petroleum hydrocarbon contamination under crop management. Journal of Soils and Sediments, 2019, vol. 19, pp. 1367-1373. Available at: https://doi.org/10.1007/s11368-018-2153-6 (accessed 12 January 2021)

21. Jafarinejad S., Jiang S.C. Current technologies and future directions for treating petroleum refineries and petrochemical plants (PRPP) wastewaters. Journal of Environmental Chemical Engineering, 2019, vol. 7, no 5, 103326. Available at: https://doi.org/ 10.1016/j.jece.2019.103326 (accessed 12 January 2021).

22. Letuvninkas A.I. Antropogennye geokhimicheskie anomalii i prirodnaya sreda [Anthropogenic geochemical anomalies and the natural environment]. Tomsk, NTL Publ., 2005. 290 p.

23. Abrosimov A.A. Ekologiya pererabotki uglevodorodnykh sistem [Ecology of processing hydrocarbon systems]. Moscow, Khimiya Publ., 2002. $608 \mathrm{p}$.

24. Kao N.-H., Su M.-C., Yen C.-C., Huang Y.-J. A characterization of the soils and sediments in contaminated sites and rivers using petroleum biomarker compounds. Journal of Soils and Sediments, 2019, no. 19, pp. 241-254.

25. Opekunova M.G. Bioindikatsiya zagryazneniy [Bioindication of pollution]. St. Petersburg, S.-Petersburg University Publ., 2004. 266 p.

26. Boev V.V., Baranovskaya N.V., Boev V.A., Yambayev M.T., Shakhova T.S., Zhornyak L.V. Change of elemental composition of soil upper horizon under the influence of oil and gas refining enterprises. Bulletin of the Tomsk Polytechnic University. Geo Assets Engineering, 2019, vol. 330, no. 11, pp. 179-191. In Rus.

27. Okhrana prirody. Pochvy. Obshchie trebovaniya $k$ otboru prob: mezhgosudarstvenny standart GOST 17.4.3.01-2017 [Conservation of nature. Soils. General requirements for sampling: interstate SS 17.4.3.01-2017]. Moscow, Standartinform Publ., 2018. 4 p.
28. Metody izucheniya lesnykh soobshchestv [Methods for studying forest communities]. St. Petersburg, NIIXimii SPbGU Publ., 2002. 240 p.

29. Rozanov B.G. Morfologiya pochv [Soil morphology]. Moscow, Akademichesky proekt Publ., 2004. $432 \mathrm{p}$

30. Fomin G.S., Fomin A.G. Pochva. Kontrol kachestva $i$ ekologicheskoy bezopasnosti po mezhdunarodnym standartam. Spravochnik [Soil. Quality control and environmental safety according to international standards. Directory]. Moscow, Gosstandart Rossii Publ., 2001. 300 p

31. Polevoy opredelitel pochv [Field determinant of soil]. Moscow, Soil Institute named after V.V. Dokuchaev Publ., 2008. 182 p.

32. Geologicheskaya karta Tyumenskoy oblasti (yuzhnye rayony). Masshtab 1:2500000 [Geological map of the Tyumen region (southern areas). Scale 1:2500000]. Available at: http://www.vsegei.ru/ru/ info/gisatlas/ufo/tyumenskaya_obl/ (accessed 12 January 2021).

33. Sudyko A.F. Opredelenie urana, toriya, skandiya i nekotorykh redkozemelnykh elementov $\mathrm{v}$ dvadtsati chetyrekh standartnykh obraztsakh sravneniya instrumentalnym neytronno-aktivatsionnym metodom [Determination of uranium, thorium, scandium and some rare-earth elements in twenty-four standard reference samples by the instrumental neutron activation method]. Radioaktivnost $i$ radioaktivnye elementy $v$ srede obitaniya cheloveka. Materialy $V$ Mezhdunarodnoy konferentsii [Radioactivity and radioactive elements in the human environment. Proc. of the V International Conference]. Tomsk, 2016. pp. 620-624.

34. Revich B.A., Saet Yu.E., Smirnova R.S. Metodicheskie rekomendatsii po otsenke stepeni zagryazneniya atmosfernogo vozdukha naselennykh punktov metallami po ikh soderzhaniyu v snezhnom pokrove i pochve (Utv. 15 maya 1990 g. № 5174-90) [Guidelines for assessing the degree of air pollution of populated areas by metals according to their content in snow cover and soil (Approved. May 15, 1990 no. 5174-90)]. Moscow, IMGRE Publ., 1990. 16 p.

35. Bogatyrev L.G., Vasilevskaya V.D., Vladychenskiy A.S. Pochvovedenie. V $2 \mathrm{ch}$. Ch. 2. Tipy pochv, ikh geografiya i ispolzovanie [Soil Science. In 2 parts. P. 2. Types of soils, their geography and use]. Moscow, Vysshaya shkola Publ., 1988. 368 p.

36. Karetin L.N. Pochvy Tyumenskoy oblasti [Soils of the Tyumen region]. Novosibirsk, Nauka Publ., 1990. 286 p.

37. Gorshenkin K.P. Pochvy yuzhnoy chasti Sibiri [Soils of the southern part of Siberia]. Moscow, AN SSSR Publ., 1955. 592 p.

38. Beznosikov V.A., Lodygin E.D., Kondratenok B.M. Assessment of background concentrations of heavy metals in soils of the northeastern part of European Russia. Eurasian Soil Science, 2007, vol. 40, no. 9, pp. 949-955. In Rus.

39. Vodyanitskiy Yu.N. rol soedineny zheleza v zakreplenii tyazhelykh metallov i metalloidov $\mathrm{v}$ pochvakh (obzor literatury) [The role of iron compounds in the fixation of heavy metals and metalloids in soils (literature review)]. Soil science, 2010, no. 5, pp. 558-572.

40. Manceau A., Marcus M.A., Tamura N. Quantitative speciation of heavy metals in soils and sediments by synchrotron X-ray techniques. Applications of synchrotron radiation in low-temperature geochemistry and environmental science. Reviews in Mineralogy and Geochemistry, 2002, vol. 49, pp. 341-428.

41. Saenko G.N. Metally $i$ galogeny $v$ morskikh organizmakh [Metals and halogens in marine organisms]. Moscow, Nauka Publ., 1992. 200 p.

42. Ivanov V.V. Ekologicheskaya geokhimiya elementov: spravochnik [Ecological Geochemistry of Elements: handbook]. Moscow, Nedra Publ., 1994. 2558 p.

43. El Bilali L., Rasmussen P.E., Hall G.E.M., Fortin D. Role of sediment composition in trace metal distribution in lake sediments. Applied Geochemistry, 2002, vol. 17, pp. 1171-1181.

44. Leuz A.-K., Monch H., Johnson C.A. Sorption of Sb (III) and Sb (V) to goethite: Influence on $\mathrm{Sb}$ (III) oxidation and mobilization. Environmental Science \& Technology, 2006, vol. 40, pp. 7277-7282.

Received: 13 October 2021.

Information about the authors

Vladislav V. Boev, Cand. Sc., assistant, Tyumen State University.

Natalia V. Baranovskaya, Dr. Sc., professor, National Research Tomsk Polytechnic University.

Viktor A. Boev, Cand. Sc., associate professor, Tyumen State University. 